University of Nebraska - Lincoln

DigitalCommons@University of Nebraska - Lincoln

USDA National Wildlife Research Center - Staff

Publications

U.S. Department of Agriculture: Animal and Plant Health Inspection Service

2017

\title{
An assessment of radiative heating as a thermal treatment for invasive snakes in cargo
}

\author{
Fred Kraus \\ University of Michigan, fkraus@umich.edu \\ Randal S. Stahl \\ USDA-APHIS-Wildlife Services, randal.s.stahl@aphis.usda.gov \\ William Pitt \\ Nathional Zoological Park
}

Follow this and additional works at: https://digitalcommons.unl.edu/icwdm_usdanwrc

Part of the Life Sciences Commons

Kraus, Fred; Stahl, Randal S.; and Pitt, William, "An assessment of radiative heating as a thermal treatment for invasive snakes in cargo" (2017). USDA National Wildlife Research Center - Staff Publications. 1943. https://digitalcommons.unl.edu/icwdm_usdanwrc/1943

This Article is brought to you for free and open access by the U.S. Department of Agriculture: Animal and Plant Health Inspection Service at DigitalCommons@University of Nebraska - Lincoln. It has been accepted for inclusion in USDA National Wildlife Research Center - Staff Publications by an authorized administrator of DigitalCommons@University of Nebraska - Lincoln. 


\title{
An assessment of radiative heating as a thermal treatment for invasive snakes in cargo
}

\author{
Fred Kraus ${ }^{\mathrm{a}}$, Randal Stahl ${ }^{\mathrm{b}}$ and William Pitt ${ }^{\mathrm{c}}$

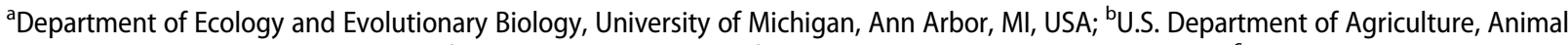

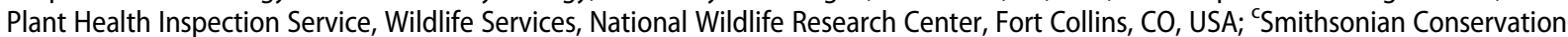 \\ Biology Institute, National Zoological Park, Front Royal, VA, USA
}

\begin{abstract}
The brown tree snake (Boiga irregularis) is invasive in Guam and presents a continuous threat of accidental export to new islands in outbound cargo. Current attempts to avoid that scenario rely primarily on canine teams to inspect outbound cargo and vehicles. In prior work, we showed that thermal fumigation could effectively elicit snake exit of cargo under conditions when free flow of air streams is feasible, but this method cannot work with tightly packed cargo. Here we show radiative heating can effectively induce snake exit from cargo refuges at temperatures of $44-48{ }^{\circ} \mathrm{C}$; however, we find passive solar heating of cargo to be unreliable in attaining sufficiently high temperatures for cargo sterilization. Although passive solar radiant heating proved unreliable, an active radiant-heating system has promise as a reliable means of treating tightly packed cargo. Times needed for treatment in a closed, controlled setting are sufficiently short that routine application of the method should provide no serious interruption of normal cargo-handling procedures.
\end{abstract}

\section{ARTICLE HISTORY}

Received 3 August 2016

Accepted 31 January 2017

\section{KEYWORDS}

Alien species; Boiga

irregularis; brown tree snake; solar heating

\section{Introduction}

The brown tree snake (Boiga irregularis) is native to the Indo-Australian islands and the northeastern margin of Australia, was introduced to Guam during or immediately after World War II in military materiel, and has negatively impacted the ecology, economy, and human health on Guam (Fritts et al. 1987, 1990, 1994; Savidge 1987; Fritts \& McCoid 1991, 1999; Rodda et al. 1997; Fritts \& Rodda 1998; Fritts \& Chiszar 1999; Fritts \& McCoid 1999; Burnett et al. 2006; Rodda \& Savidge 2007; Shwiff et al. 2010). The high population densities of these snakes on Guam and their proclivity for hiding in small spaces make their transport in cargo or vehicles to other locations from Guam an ever-present threat. To mitigate that threat, for more than 20 years, the U.S. Department of Agriculture has had a program on Guam to inspect departing cargo and vehicles to ensure that snakes are not inadvertently exported. These inspections rely on a combination of visual searches and canine detector teams (Engeman et al. 1998, 2002; Vice et al. 2009). Because these methods cannot be perfectly effective, developing additional means to sanitize cargo and vehicles is highly desirable as a means of further reducing the risk of off-island transport.

To that end, recent work has shown that brown tree snakes can easily be induced to exit experimental refuges using streams of heated air (Kraus et al. 2015a).
This is unsurprising because snakes are sensitive to avoiding extreme temperatures, and it has been found that brown tree snakes will die if exposed to temperatures of $41{ }^{\circ} \mathrm{C}$ for $1 \mathrm{~h}$ (Christy et al. 2007). Temperatures we found effective for fumigation are sufficiently low $\left(\sim 48-50^{\circ} \mathrm{C}\right)$ and applied for such short periods $(<5 \mathrm{~min}$ ) that damage to packaged goods should be non-existent. However, this treatment method can only be used to elicit exit of snakes from refuges connecting to open airways that allow the free flow of air past the snakes. Hence, this method may be a viable means of treating munitions, break-bulk cargo, airplane wheel wells, and other vehicles that have an interconnected void volume (Kraus et al. 2015a). In the case of packed cargo pallets and containers, however, contents are often tightly packed such that heated air cannot freely enter all enclosed spaces. In such circumstances, use of heated airstreams will be ineffective as a fumigant for snakes. Because a large volume of cargo leaves Guam for other destinations, this makes it desirable to find a cargo-treatment method that does not require free air flow. Failing this, outbound cargo will continue to pose a major risk of snake transport to other regions of the Pacific, mitigated only by canine inspections.

The use of chemicals for snake fumigation is also infeasible because it suffers from a number of logistical limitations (Kraus et al. 2015b); hence, the use of 
heat would still be a desirable treatment method because of its safety, ease of application, and relatively low cost. In assessing further heat-treatment options besides using blown air, it is important to consider that heat may be applied to a sequestered snake by three mechanisms: via convection, conduction, or thermal radiation. Convection involves heat transfer through a fluid or gas by mass transport in currents, conduction involves transfer of heat between adjacent molecules without mass motion of the medium through which energy transfer is occurring, and thermal radiation involves energy transfer via electromagnetic radiation. In the context of treating cargo refuges for snakes, convection involves the use of air as the medium of heat transfer, conduction involves direct heat transfer between a snake and cargo contents in contact with it, and thermal radiation involves absorption of both long- and shortwave radiation from the environment by the cargo contents and its emittance to the snake as long-wave (thermal) energy. Because each operates via a different physical mechanism, the differing resistances involved require empirical evaluation to determine their feasibility for use as treatment methods.

Our earlier work showed the reliability of convective heating for eliciting exit of snakes from refuges when air could pass freely over them (Kraus et al. 2015a). But the closely packed configuration of cargo contents prohibits the use of this convective mechanism for heat fumigation in that circumstance. Despite this, it remains to be seen whether conduction or thermal radiation can provide a useful alternative means of heat treatment for snakes in cargo. An earlier study of 20-foot sea-going containers leaving Guam found that passive solar irradiance during transit was insufficient to guarantee lethal temperatures to snakes (Perry \& Vice 2007). However, these containers have much larger mass than containers used in air transport, and it is reasonable to yet inquire whether passive solar heating could prove feasible for treating smaller containers and pallets. Because both conduction and thermal radiation require heating of cargo from an outside energy source, a further question is whether heat application must be active or whether it could rely on passive heating by the sun. We designed the present study to investigate these possibilities. Herein we investigate the feasibility of thermal radiation - both passively and actively delivered - as a means of treating air-borne cargo for pest snakes. It should be borne in mind that for the purposes of sterilizing outbound cargo for snakes, it does not matter whether the treatment method kills snakes or merely elicits their exit from the cargo prior to shipping. Either result would provide an effective form of cargo treatment to prevent brown tree snakes from accidentally leaving Guam.

\section{Materials and methods}

\section{Passive solar heating}

We placed temperature-recording Hobo loggers (Pro V2) in a variety of types of cargo pallets and containers sitting exposed on the tarmac on Andersen Air Force Base (AAFB), Guam. We recorded temperatures in these pallets/containers for approximately $7 \mathrm{~h}$ across the hottest part of the day (from $\sim 0900$ to $1600 \mathrm{~h}$ ). Each logger contained two temperature sensors - one internal to the body of the unit and one at the end of $183-\mathrm{cm}$ cable. We taped the external probe of each Hobo logger to one end of a $122-\mathrm{cm}$ fiberglass pole, leaving the body of the logger with the internal probe hanging from the other end of the pole. We then inserted the external probe into the interior of cargo pallets while leaving the internal probe on the outer margin of the pallet yet under the heavy tarps that covered most cargo pallets (Figure 1(a,b)). This allowed us to measure how the temperature changed across a horizontal profile from a pallet's surface to its interior.

We placed probes inside the following types of pallets and containers: standard $100 \times 122 \mathrm{~cm}$ pallets, tall 463-L pallets, LD3 containers, ISU-70 containers, and ISU-90 containers. The pallets consist of stacked cargo tied down onto standard plywood pallet frames (Figure 1(a)) that may be covered with an outer tarp (Figure 1(b)); LD-3's are small, single-walled, enclosed, aluminum and plastic-fiber containers (Figure 1(c)); and the ISUs are large steel-enclosed containers painted olive green or brown (Figure 1(d)). We also placed probes in commercial generators and NF2D light carts because each is commonly available at AAFB and provides the opportunity for snake refuge; both are large metal items painted externally olive green or gray and with internal metal components and open spaces providing potential refuge for snakes. For pallets, we placed probes in vertically stratified locations near the top, center, or bottom of each pallet, with each logger recording both internal and external temperatures. Probes placed near the top were never placed along the top outside surface but were instead inserted approximately $30-50 \mathrm{~cm}$ below the top surface; those placed near the bottom varied from being on the top of the pallet surface to $30 \mathrm{~cm}$ above that surface. Spaces within containers, generators, and light carts were enclosed by their metal sides, so probes could only be placed internally at either top, center, or bottom positions.

We noted weather conditions during each day of trials, but could not obtain data on total sunlight flux due to repeated equipment failures. To compensate for this we acquired the Climate Report from the National Weather Service for the months of January through December for the weather station at the Guam International Airport. The data can be accessed 


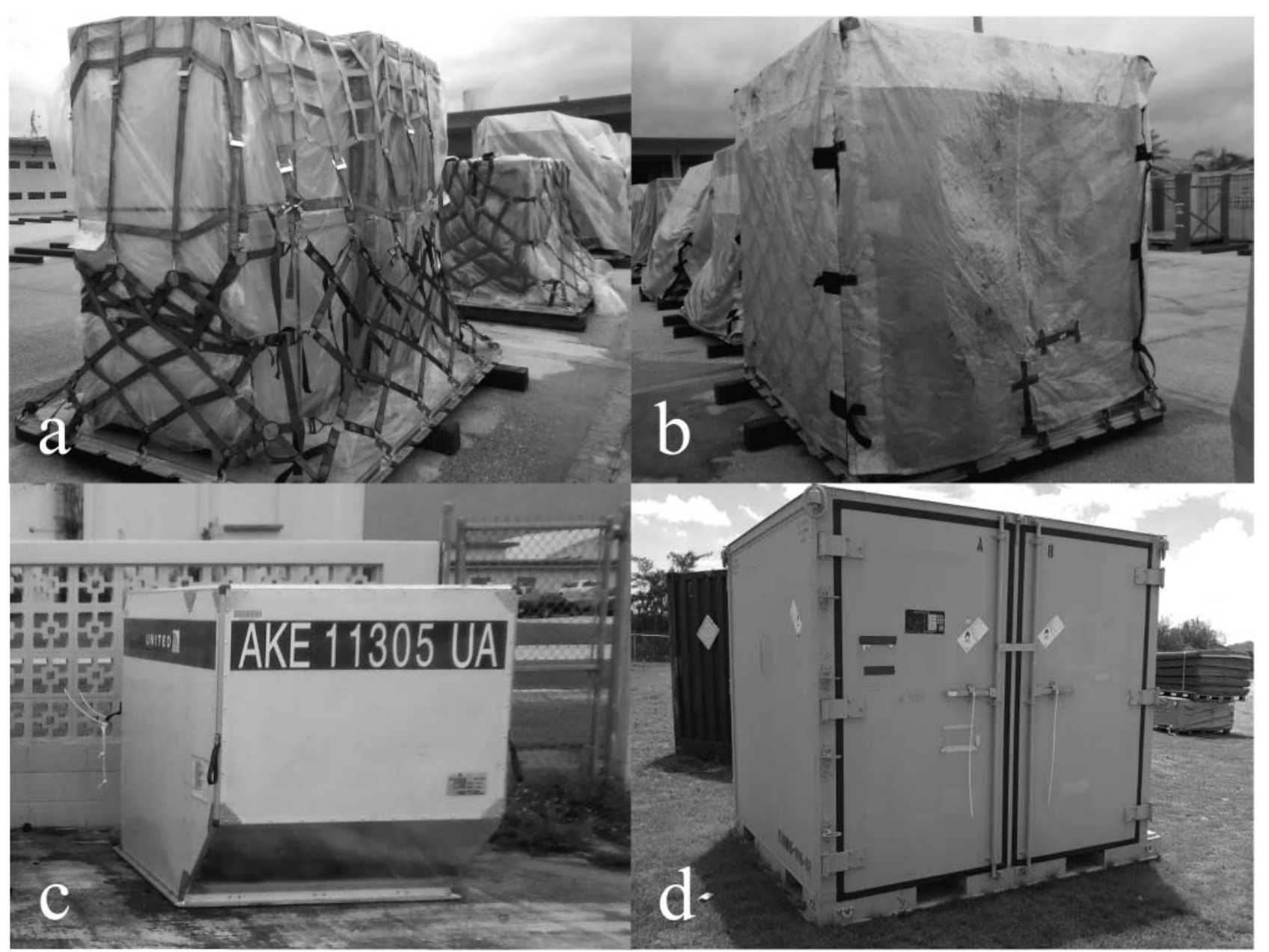

Figure 1. Examples of the cargo pallets and containers tested for passive-heating efficacy: (a) standard tall pallets shrink-wrapped to transport military household goods; (b) tall pallets covered with protective tarps; (c) LD-3 container frequently used to transport commercial air cargo; and (d) ISU-90 used to transport military cargo.

at http://w2.weather.gov/climate/index.php?wfo=guam. These are data averaged over a 30-year period from 1981 to 2010. Data collected from each monthly report included average sky cover, number of days cloudy, number of days partly cloudy, and number of days with rain. We also took representative irradiance readings $\left(\mathrm{W} / \mathrm{m}^{2}\right)$ during different weather conditions using either a Decagon Devices Model PYR Solar Radiation Sensor or a Commercial Electric MAS830B multimeter.

We abstracted from our Hobo logger data streams data on the highest temperature achieved by each probe and length of time each probe spent at $41^{\circ} \mathrm{C}$ or higher. We summarized and graphed these data to assess the frequency and duration for which cargo pallets and containers reached lethal temperatures for brown tree snakes.

\section{Radiation experiments}

\section{Test site and animals}

We conducted tests on Guam in a warehouse on AAFB at ambient air temperatures $\left(26-31{ }^{\circ} \mathrm{C}\right)$. Snakes were retained in a communal cage for at least one day prior to use, were kept in shade at all times, and had drinking water provided ad libitum. We determined the sex of each snake by probing for hemipenes, measured its snout-vent length to the nearest $1 \mathrm{~mm}$, and transferred it to an individual 14.2-L container that served as a test refuge. We then gave snakes at least $1 \mathrm{~h}$ to calm down prior to testing, although most snakes were left overnight in the container prior to testing. All applicable international, national, and/or institutional guidelines for the care and use of animals were followed as approved by NWRC's Institutional Animal Care and Use Committee under protocols QA-2312 and QA-2528.

\section{Test apparatus}

In November 2015, we tested snakes inside an experimental refuge modified from that used by Kraus et al. (2015a), which consisted of a commercially available translucent polyethylene container measuring $17 \mathrm{~cm} \times$ $33 \mathrm{~cm} \times 42 \mathrm{~cm}$ and having a volume of $14.2 \mathrm{~L}$ (Figure 2 (a,b,d)). We drilled a 7.5-cm-diameter exit hole that abutted flush onto an aluminum exit pipe faced with glass and having dimensions $7 \mathrm{~cm} \times 10 \mathrm{~cm} \times 152 \mathrm{~cm}$ 

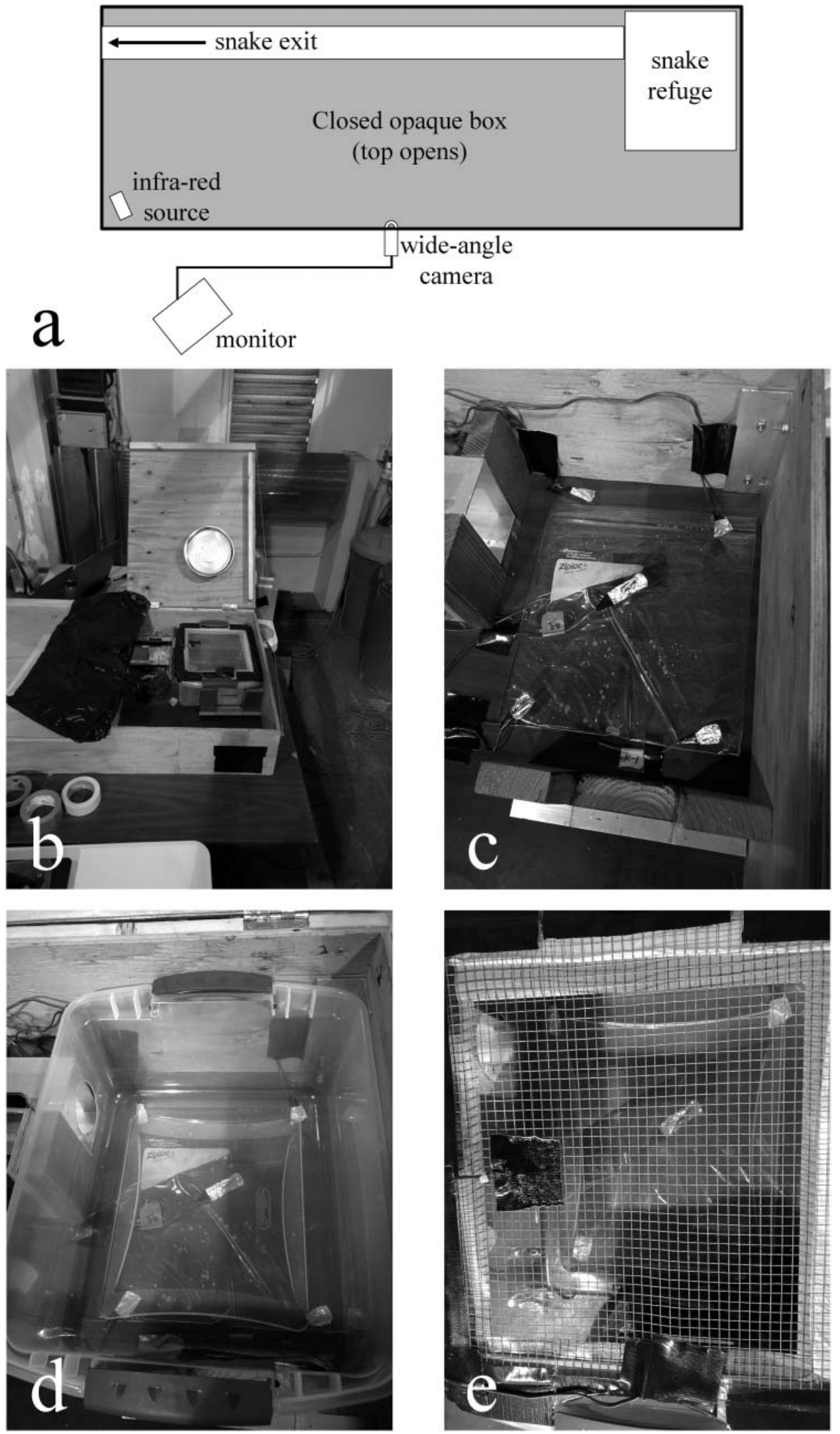

Figure 2. Design of the test apparatus used for the radiative-heat trials: (a) schematic of the apparatus in dorsal view; (b) frontal view of the right half of the apparatus with the rightmost lid open to show placement of the infrafred lamp and the test refuge in situ; (c) close-up view into the apparatus showing where the test refuge is placed, showing placement of the thermocouple leads below the center and each corner of the refuge and the bag with $300 \mathrm{~mL}$ of water; (d) close-up view of the test refuge in place in the apparatus over the water and bottom thermocouples; and (e) close-up view of the screen lid placed over the refuge, showing placement of the thermocouple probes placed on the lid (left side) and projecting through the lid to sample air temperature (bottom). 
and a volume of 10.4 L (Figure 2(a)). In contrast to the study of Kraus et al. (2015a), we modified the solid polyethylene lid of the refuge by removing the center and covering it securely with hardware cloth (Figure 2 $(\mathrm{b}, \mathrm{e})$ ). This allowed for easy transfer of radiant energy during the trials. We then fixed the test container and exit pipe inside a wooden box with closable lid to allow the experiments to be conducted in darkness (Figure 2 $(a, b))$. In the top of the wooden box, we made a circular opening into which we fit an infrared lamp in a reflector that was taped securely into place around its perimeter to prevent light leaks (Figure 2(b)). We used a $100-\mathrm{W}$ infrared bulb for all trials. When that lid was lowered to close the experimental box, the infrared bulb was situated approximately $2 \mathrm{~cm}$ above the hardware cloth of the refuge lid. By housing the refuge in darkness, we could be assured that the experimental subjects were not responding to stimuli other than the infrared-radiation treatments. We fitted an infrared camera connected to a video monitor into the front of the box so we could monitor activities of the test subjects; we placed a small, low-energy infrared lamp in the corner opposite the refuge to provide illumination (Figure 2(a)).

For each test we taped a thermocouple wire to the table top below the center of the refuge, another to the outside bottom of the refuge under the infrared source, a third to the hardware-cloth lid of the refuge approximately $8 \mathrm{~cm}$ to the side of the infrared source, and a fourth probe projecting in the air approximately $8 \mathrm{~cm}$ into the refuge from the exit tube (Figure 2(c,e)). These allowed us to record sets of instantaneous temperature readings adjacent to the heat source, at the surface opposite the heat source, and in the air to the side of the heat source. Temperature was measured using 24gauge type- $\mathrm{T}$ thermocouples (Omega Engineering, Inc., Stanford, CT) recorded with Signal Express software using an NI-DAQ interface containing a thermocouple input module (National Instruments, Austin, TX). Temperature data were collected for the thermocouples simultaneously at $1 \mathrm{~s}$ intervals across the duration of each trial. Data were exported to MS Excel following each trial for subsequent processing prior to analysis in R (Version 3.2.3; R Foundation for Statistical Computing, CRAN.Rproject.org).

We conducted two sets of experiments providing different thermal-absorption environments:

(1) Forty trials with the polyethylene refuge sitting directly on the bench-top to provide an environment in which the bottom of the chamber heated more rapidly than the air.

(2) Thirty trials with a plastic Ziploc bag filled with $330 \mathrm{~mL}$ of water lying between the polyethylene refuge and the bench-top (Figure 2(c)) to increase the thermal mass of the bottom of the chamber and allow the air to heat more rapidly than the bottom. For experiment (2), 14 trials used the same arrangement of thermocouple probes as noted above, and for the remaining 16 trials, we added one additional probe to each of the bottom four corners of the refuge (Figure 2(c)).

\section{Test procedure}

At the start of each test, we introduced one of the 14.2-L containers in which a snake had been acclimated into the enclosing test apparatus, gently replaced its solid lid with the screened lid holding the top thermocouple probe, and closed the box, placing the snake in darkness and bringing the infrared source adjacent to the refuge lid. We turned on the infrared camera and monitor, the thermocouple recording device, and, finally, the infrared source. We used a stopwatch to record to the nearest second times to (1) the first snake movement, and (2) the exit of snake from the refuge. Upon snake exit from the refuge, the trial was terminated and the snake removed from the test apparatus.

\section{Data}

We used the measured air temperature, refuge-floor temperature, and refuge-top temperatures to calculate a thermally equivalent temperature $\left(T_{e}\right)$ that mathematically describes the total radiant energy exchange between the snake and its environment approximating the wall temperature of a black-body cavity containing the snake:

$$
T_{e}=T_{a}+r_{e}\left(R_{\mathrm{abs}}-\varepsilon \sigma T_{a}^{4}\right) / \rho c_{p}(\text { Campbell 1977, eqn } 7.17)
$$

where $T_{a}$ is the air temperature, $R_{\mathrm{abs}}$ is the total amount of long- and short-wave radiation, $\varepsilon$ is the emissivity of the air, $\sigma$ is the Stephan-Boltzmann constant, $\rho$ is the density of the air, $c_{p}$ is the specific heat of air, and $r_{e}$ is a parallel resistance term combining both sensible and radiative transfer resistances. The minimum radiant environment corresponds to the longwave radiation transfer (IR) of heat from the refuge walls to the snake as the studies are conducted in the dark (Campbell 1977, eqn 7.11). The emissivity $(\varepsilon)$ term in that equation is an average across all surface types and $a$ is the absorptivity coefficient for radiation by the snake, in this case only long-wave radiation. This value is added to the temperature contribution from the air. We calculated $T_{e}$ for each time point in each trial for which both air and refuge-wall temperatures were measured. We calculated the rate of change of $T_{e}\left(\mathrm{~d} T_{e} / \mathrm{d} t\right)$ by dividing the change in $T_{e}$ between trial onset and time to exit the refuge by that time interval. We calculated these values for each trial across all treatment groups. We also calculated the total heat input in $\mathrm{kJ}$, using the equation $Q=m$. $C_{p} \cdot \mathrm{d} T$, where $Q$ is the heat capacity, $m$ is the air mass $(\mathrm{kg}), C_{p}$ is the specific heat of air on a unit mass basis 
$\mathrm{kJ} /(\mathrm{kg} \cdot \mathrm{C})$, and $\mathrm{d} T$ is the change in temperature in ${ }^{\circ} \mathrm{C}$ (Olmsted \& Williams 1997).

We used a principal components analysis (PCA) using the R library's chemometrics and pcaPP to identify snake trials that were outliers after data were median centered. Outliers were removed from subsequent statistical analysis. We used $F$-tests to test for equal variances between samples and used $t$-tests with Bonferroni correction to test for response-time and response-temperature differences with body size, sex, and treatment group. We constructed regression models in $R$ to evaluate the effects of air temperature, refuge bottom temperature, and an interaction term on the time of exit observed in the two treatments. We ranked models using the corrected Akaike Information Criterion $\left(\mathrm{AIC}_{\mathrm{c}}\right)$, selected the best models based on the smallest $\triangle \mathrm{AICc}$, and used Akaike weights $\left(w_{i}\right)$ to assess the weight of evidence in favor of a model after Anderson (2007).

We used our results to model heating scenarios for four different pallet configurations containing items of widely varying densities and specific heats (paper towels, packaged bottled water, electrical junction boxes, and large steel tool chests) so as to estimate the amount of time required to thoroughly heat the respective pallets to a temperature of either 41 or $47.7^{\circ} \mathrm{C}$, assuming a starting temperature of $30^{\circ} \mathrm{C}$. These scenarios assumed the pallet was placed in a chamber where the walls of the chamber were maintained at either 41 or $47.7^{\circ} \mathrm{C}$, the first reflecting a $T_{e}$ at the upper lethal temperature for the brown tree snake (Christy et al. 2007), and the second reflecting our calculations of average $T_{e}$ at the times of snake exit in these trials (see Results). These calculations depend on the surface area of the pallet $\left(\mathrm{m}^{2}\right)$, the total mass of the pallet $(\mathrm{kg})$, and the specific heat of the material on the pallet $(\mathrm{kJ} \mathrm{K} / \mathrm{kg})$. The chamber walls radiate long-wave radiation at a constant energy output, and the pallet absorbs this radiation at a rate proportional to surface area. The time needed to attain 41 or $47.7^{\circ} \mathrm{C}$ is calculated as the difference between the starting and final temperatures.
Table 1. Characteristics of the pallets, containers, and machinery tested.

\begin{tabular}{lcccc}
\hline Cargo type & $\begin{array}{c}\text { Number } \\
\text { examined }\end{array}$ & $\begin{array}{c}\text { Minimum } \\
\text { mass }(\mathrm{kg})\end{array}$ & $\begin{array}{c}\text { Maximum } \\
\text { mass }(\mathrm{kg})\end{array}$ & $\begin{array}{c}\text { Average } \\
\text { mass }(\mathrm{kg})\end{array}$ \\
\hline Tall pallet & 33 & 655 & 1705 & 1095 \\
Short pallet & 4 & 167 & 2993 & 1705 \\
Steel pallet & 4 & 299 & 545 & 424 \\
Empty LD-3 & 15 & 60 & 60 & 60 \\
ISU-70 & 9 & 1718 & 2082 & 1905 \\
ISU-90 & 3 & 755 & 709 & 724 \\
Generator & 6 & 3364 & 12,273 & 5097 \\
NF2D light cart & 7 & unknown & unknown & unknown \\
\hline
\end{tabular}

\section{Results}

\section{Passive solar heating}

We collected data at 336 locations in 80 cargo pallets, containers, generators, or light carts offering potential snake refuges over 17 days in December 2014, MayJune 2015, and November 2015. Tested objects varied from $60 \mathrm{~kg}$ for empty LD3 containers to $12,273 \mathrm{~kg}$ for the largest generator (Table 1). Pallets and ISU containers were packed with cargo, LD3 containers were empty, and light carts and generators were large machinery items not designed for cargo storage but having large internal air spaces that could serve as snake refuges.

The percentages of probes reaching a lethal temperature for brown tree snakes $\left(41{ }^{\circ} \mathrm{C}\right)$ varied tremendously, ranging from $0 \%$ to $100 \%$, depending on vertical (Table 2) or horizontal (Table 3) location. The greatest success in passively warming to a temperature lethal to brown tree snakes was along the tops of several types of metal containers, the tops of tall $463-\mathrm{L}$ pallets, and the outsides of steel pallets (Tables 2, 3). However, none of these container/pallet types achieved uniformly lethal temperatures throughout, with the best overall heating being seen in some of the metal containers (Table 3).

Furthermore, even if a temperature of $41{ }^{\circ} \mathrm{C}$ was achieved by passive solar radiation, durations at or above that temperature were highly variable, ranging from 1 to $432 \mathrm{~min}$ (Tables 2 and 3). With the exception of ISU-90 containers, fewer than half of all probes

Table 2. Success rate in reaching lethal temperatures for brown tree snakes by vertical location. Values for lethal durations are only for those trials reaching lethal temperatures, given as mean (range).

\begin{tabular}{|c|c|c|c|c|c|c|}
\hline \multirow[b]{3}{*}{ Cargo type } & \multicolumn{6}{|c|}{ Probe location } \\
\hline & \multicolumn{2}{|c|}{ Top } & \multicolumn{2}{|c|}{ Center } & \multicolumn{2}{|c|}{ Bottom } \\
\hline & $\%$ reaching $41^{\circ} \mathrm{C}$ & Lethal duration (min) & $\%$ reaching $41{ }^{\circ} \mathrm{C}$ & Lethal duration (min) & $\%$ reaching $41{ }^{\circ} \mathrm{C}$ & Lethal duration (min) \\
\hline Tall pallet & $54(18 / 33)$ & $204(1-414)$ & $32(12 / 38)$ & 175 (12-389) & $16(10 / 62)$ & $128(37-225)$ \\
\hline Short pallet & $0(0 / 4)$ & 0 & NA & NA & $11(1 / 9)$ & 251 \\
\hline Steel pallet & NA & NA & NA & NA & $50(4 / 8)$ & $147(16-289)$ \\
\hline Empty LD-3 & $70(14 / 20)$ & $196(4-415)$ & NA & NA & $24(8 / 34)$ & $180(51-326)$ \\
\hline ISU-70 & $56(9 / 16)$ & $152(55-295)$ & $0(0-8)$ & 0 & $15(3 / 20)$ & 137 (126-146) \\
\hline ISU-90 & NA & NA & $92(11 / 12)$ & $280(47-432)$ & $42(5 / 12)$ & $221(70-297)$ \\
\hline Generator & $20(2 / 10)$ & $68(41-96)$ & $0(0 / 2)$ & 0 & $0(0 / 14)$ & 0 \\
\hline NF2D light cart & $60(6 / 10)$ & $28.7(2-71)$ & $0(0 / 2)$ & 0 & $8(1 / 12)$ & 45 \\
\hline
\end{tabular}


Table 3. Success rate in reaching lethal temperatures for brown tree snakes by horizontal location. Values for lethal durations are only for those trials reaching lethal temperatures, given as mean (range).

\begin{tabular}{|c|c|c|c|c|}
\hline \multirow[b]{3}{*}{ Cargo type } & \multicolumn{4}{|c|}{ Probe location } \\
\hline & \multicolumn{2}{|c|}{ Inside } & \multicolumn{2}{|c|}{ Outside } \\
\hline & $\begin{array}{c}\% \text { reaching } \\
411^{\circ} \mathrm{C}\end{array}$ & $\begin{array}{l}\text { Lethal } \\
\text { duration } \\
\text { (min) }\end{array}$ & $\begin{array}{c}\% \text { reaching } \\
411^{\circ} \mathrm{C}\end{array}$ & $\begin{array}{l}\text { Lethal } \\
\text { duration } \\
\text { (min) }\end{array}$ \\
\hline Tall pallet & $20(14 / 71)$ & $251(1-414)$ & $42(26 / 62)$ & $136(1-366)$ \\
\hline Short pallet & $0(0 / 6)$ & 0 & $17(1 / 6)$ & 251 \\
\hline Steel pallet & $0(0 / 4)$ & 0 & $100(4 / 4)$ & 191 (16-289) \\
\hline Empty LD-3 & $41(22 / 54)$ & $190(4-415)$ & NA & NA \\
\hline ISU-70 & $32(16 / 50)$ & $162(55-295)$ & NA & NA \\
\hline ISU-90 & $67(16 / 24)$ & $262(47-432)$ & NA & NA \\
\hline Generator & $11(3 / 28)$ & $50(14-96)$ & NA & NA \\
\hline $\begin{array}{l}\text { NF2D light } \\
\text { cart }\end{array}$ & $29(7 / 24)$ & $31(2-71)$ & NA & NA \\
\hline
\end{tabular}

Table 4. Percentage of trials achieving a lethal temperature of $41^{\circ} \mathrm{C}$ for at least one hour.

\begin{tabular}{lccccc}
\hline & \multicolumn{5}{c}{ Probe location } \\
\cline { 2 - 6 } Cargo type & Top & Center & Bottom & Inside & Outside \\
\hline Tall pallet & $42(14 / 33)$ & $21(8 / 38)$ & $13(8 / 61)$ & $17(12 / 71)$ & $30(18 / 61)$ \\
Short pallet & $0(0 / 4)$ & NA & $12(1 / 8)$ & $0(0 / 6)$ & $17(1 / 6)$ \\
Steel pallet & NA & NA & $38(3 / 8)$ & $0(0 / 4)$ & $75(3 / 4)$ \\
Empty LD-3 & $40(8 / 20)$ & NA & $18(6 / 34)$ & $26(14 / 54)$ & NA \\
ISU-70 & $50(8 / 16)$ & $0(0 / 8)$ & $15(3 / 20)$ & $30(15 / 50)$ & NA \\
ISU-90 & NA & $83(10 / 12)$ & $42(5 / 12)$ & $62(15 / 24)$ & NA \\
Generator & $10(1 / 10)$ & $0(0 / 2)$ & $0(0 / 14)$ & $4(1 / 28)$ & NA \\
NF2D light & $10(1 / 10)$ & $0(0 / 2)$ & $0(0 / 12)$ & $4(1 / 24)$ & NA \\
cart & & & & & \\
\hline
\end{tabular}

sustained a lethal temperature for an hour or more (Table 4), the time needed to kill a brown tree snake. With the exception of two empty LD3 containers, none of the cargo units attained a consistent temperature of $41{ }^{\circ} \mathrm{C}$ throughout the unit. Typically, the bottom inside portions of pallets and containers failed to reach lethal temperatures and, hence, would provide safe thermal refuges for snakes.

Monthly cloud cover averaged $30 \%-40 \%$ of the sky, and the majority of days in a month have some degree of cloud cover (Table 5). Solar irradiance at noon is $1200 \mathrm{~W} / \mathrm{m}^{2}$ on a clear day with no clouds in the sky (Campbell 1977). Under cloudy conditions, depending on the cloud type (e.g. cirrus, altocumulus, stratus, etc.) and coverage, irradiance may range from a maximum of $\sim 1000 \mathrm{~W} / \mathrm{m}^{2}$ to less than $200 \mathrm{~W} / \mathrm{m}^{2}$. From a maximum at solar noon, the decreasing angle of solar elevation decreases irradiance over the day. We obtained average solar irradiance values from $472-632 \mathrm{~W} / \mathrm{m}^{2}$ for three days in which we were able to obtain recordings throughout the day under partly cloudy conditions. We obtained single-point readings (not daily averages) of 130-215 $\mathrm{W} / \mathrm{m}^{2}$ under heavy cloud cover, $370-645 \mathrm{~W} / \mathrm{m}^{2}$ in partly cloudy conditions, and $600-990 \mathrm{~W} / \mathrm{m}^{2}$ in direct sunlight. Based on our data, daily averages on Guam are likely to be $<1000 \mathrm{~W} / \mathrm{m}^{2}$ for most days of the year.
Table 5. Monthly 30-year average (1981-2010) summary climate data for the Guam International Airport.

\begin{tabular}{lccccc}
\hline Month & $\begin{array}{c}\text { Sky } \\
\text { Cover } \\
(0-1)\end{array}$ & $\begin{array}{c}\text { Number } \\
\text { of fair } \\
\text { days }\end{array}$ & $\begin{array}{c}\text { Number } \\
\text { of partly } \\
\text { cloudy days }\end{array}$ & $\begin{array}{c}\text { Number } \\
\text { of overcast } \\
\text { days }\end{array}$ & $\begin{array}{c}\text { Number } \\
\text { of days } \\
\text { with rain }\end{array}$ \\
\hline January & 0.40 & 14 & 14 & 3 & 10 \\
February & 0.50 & 9 & 18 & 2 & 9 \\
March & 0.40 & 18 & 12 & 1 & 3 \\
April & 0.50 & 10 & 17 & 3 & 10 \\
May & NA & NA & NA & NA & NA \\
June & 0.30 & 19 & 11 & 0 & 7 \\
July & 0.40 & 21 & 8 & 2 & 12 \\
August & 0.40 & 12 & 17 & 2 & 13 \\
September & NA & NA & NA & NA & NA \\
October & 0.40 & 14 & 12 & 2 & 8 \\
November & 0.40 & 18 & 11 & 1 & 11 \\
December & 0.40 & 13 & 17 & 0 & 11 \\
\hline
\end{tabular}

\section{Radiation experiments}

In our trials, we found no sexual differences in snoutvent length, time to exit refuge, air temperature at time of refuge exit, or bottom temperature at time of refuge exit. Snakes used in the trials with the water bag averaged somewhat smaller than snakes used for the trials with no water (Table 6), but this merely reflects the fact that larger snakes were used before resorting to smaller snakes, and the set of no-water trials were conducted first.

Times at first observed snake movement and times at exit from the refuge varied tremendously (511451 s), with time at first movement being less for the trials without the buffering water bag than in those trials using the water bag (Table 6). Bottom temperatures at times of first movement and refuge exit ranged from $33-57^{\circ} \mathrm{C}$ and presented a wider range than did air temperatures at these same behavioral landmarks (31-48 ${ }^{\circ} \mathrm{C}$, Table 6). Bottom temperatures differed significantly at these behavioral landmarks between the two treatment types, but air temperatures differed significantly between treatment types only for first observed snake movement (Table 6). Air temperatures at time of refuge exit did not differ between the two treatments.

For trials conducted without water bags, the model incorporating only air temperature had the lowest $\Delta \mathrm{AIC}_{\mathrm{c}}$ value, but is only twice as likely as the models using only bottom temperature or both air and bottom temperatures (Table 7). For trials conducted with the water bags, the best-fit model incorporated both the air and bottom temperatures as well as an interaction term between them (Table 7). Again, however, the model using bottom temperature alone is a competing model. An important point in interpreting these models is that air temperature and bottom temperature are not truly independent variables inasmuch as conduction and convection at the air/bottom interface are not uncoupled in these measurements.

The complexity of the thermal environment, and the models explaining behavior for both treatments, is 
Table 6. Snake responses (mean $\pm 1 \mathrm{SD}$ ) in the heat trials with and without a water buffer under the refuge.

\begin{tabular}{|c|c|c|c|c|c|}
\hline \multirow[b]{2}{*}{ Comparison } & \multicolumn{5}{|c|}{ Treatment } \\
\hline & Water bag & $\mathrm{N}$ & No water bag & $\mathrm{N}$ & $p$ \\
\hline Snout-vent length & $998 \pm 91.3(884-1213)$ & 30 & $1074 \pm 117.8(850-1352)$ & 35 & 0.0056 \\
\hline Time $_{\text {first movement }}$ & $654.0 \pm 285.2(51-972)$ & 28 & $451.5 \pm 250.5(195-1242)$ & 31 & $\leq 0.0056$ \\
\hline Time $_{\text {exit }}$ & $858.1 \pm 325.7(320-1451)$ & 30 & $782.5 \pm 269.7(180-1289)$ & 35 & 0.31 \\
\hline Bottom $T_{\text {first movement }}$ & $41.3 \pm 3.0(33.3-54.9)$ & 28 & $42.3 \pm 5.9(334.7-47.4)$ & 31 & $\leq 2.2 \mathrm{e}^{-16}$ \\
\hline Bottom $T_{\text {exit }}$ & $42.9 \pm 2.8(37.0-48.2)$ & 30 & $50.5 \pm 4.3(40.3-57.2)$ & 35 & $\leq 7.3 \mathrm{e}^{-12}$ \\
\hline Air $T_{\text {first movement }}$ & $40.0 \pm 2.6(30.9-48.3)$ & 28 & $38.2 \pm 4.5(34.7-43.7)$ & 31 & $\leq 0.061$ \\
\hline Air $\mathrm{T}^{\circ}{ }_{\text {exit }}$ & $41.3 \pm 2.2(36.8-44.6)$ & 30 & $41.9 \pm 3.7(32.3-48.5)$ & 35 & 0.49 \\
\hline
\end{tabular}

Table 7. Performance of models evaluating the relationship between air temperature and bottom temperature at the time of refuge exit by snakes for the two treatments. $K$ is the number of parameters in the model; Adj. $R^{2}$ is the $R^{2}$ value adjusted for the number of parameters in the model and accounts for the amount of variation explained by the model; $\mathrm{AIC}_{\mathrm{c}}$ is Akaike's information criterion adjusted for small sample size; $\Delta \mathrm{AIC}_{\mathrm{c}}$ is the calculated difference in the $\mathrm{AIC}_{\mathrm{c}}$ of the best model and the selected model; $w_{i}$ are the $\mathrm{AIC}_{\mathrm{c}}$ weights, which reflect the relative support for each model.

\begin{tabular}{|c|c|c|c|c|c|}
\hline Model & $K$ & Adj. $R^{2}$ & $\mathrm{AlC}_{\mathrm{c}}$ & $\Delta \mathrm{AIC}_{\mathrm{c}}$ & $w_{i}$ \\
\hline \multicolumn{6}{|c|}{ No water treatment } \\
\hline Air temperature & 2 & 0.56 & 161.1 & 0 & 0.46 \\
\hline Bottom temperature & 2 & 0.52 & 162.6 & 1.5 & 0.22 \\
\hline $\begin{array}{l}\text { Air temperature + bottom } \\
\text { temperature }\end{array}$ & 3 & 0.58 & 162.5 & 1.4 & 0.23 \\
\hline $\begin{array}{l}\text { Air temperature }+ \text { bottom } \\
\text { temperature }+ \text { air } * \text { bottom } \\
\text { temperature }\end{array}$ & 4 & 0.59 & 164.3 & 3.2 & 0.09 \\
\hline \multicolumn{6}{|c|}{ Water treatment } \\
\hline Air temperature & 2 & 0.64 & 140.9 & 10.6 & 0.0025 \\
\hline Bottom temperature & 2 & 0.83 & 131.0 & 0.7 & 0.35 \\
\hline $\begin{array}{l}\text { Air temperature }+ \text { bottom } \\
\text { temperature }\end{array}$ & 3 & 0.84 & 132.7 & 2.4 & 0.15 \\
\hline $\begin{array}{l}\text { Air temperature }+ \text { bottom } \\
\text { temperature }+ \text { air } * \text { bottom temp }\end{array}$ & 4 & 0.88 & 130.3 & 0 & 0.50 \\
\hline
\end{tabular}

dependent on both the heating rate and the final temperature of the bottom center of the refuge. This is due to the unidirectional energy input from the heat lamp, with temperatures at this location being much higher in the trials with no water bag (Figure 3(a)) than in those having the buffering water layer (Figure 3(b,c)). Despite those differences, the total energy environments that the snakes responded to were remarkably similar, with snakes first moving at an average $T_{e}$ of 44.4-46.8 ${ }^{\circ} \mathrm{C}$ and exiting the refuge at an average of $T_{e}$ 47.4-47.9 ${ }^{\circ} \mathrm{C}$ (Table 8). These correspond to narrow ranges of emittance at $T_{e}$ as well (534-620 $\mathrm{W} \mathrm{m}$, Table 8).

Knowing the upper lethal temperature for brown tree snakes $\left(41{ }^{\circ} \mathrm{C}\right)$, energy environments at which snakes respond to radiative warming (Table 8 ), and the physical properties of cargo contents, one can

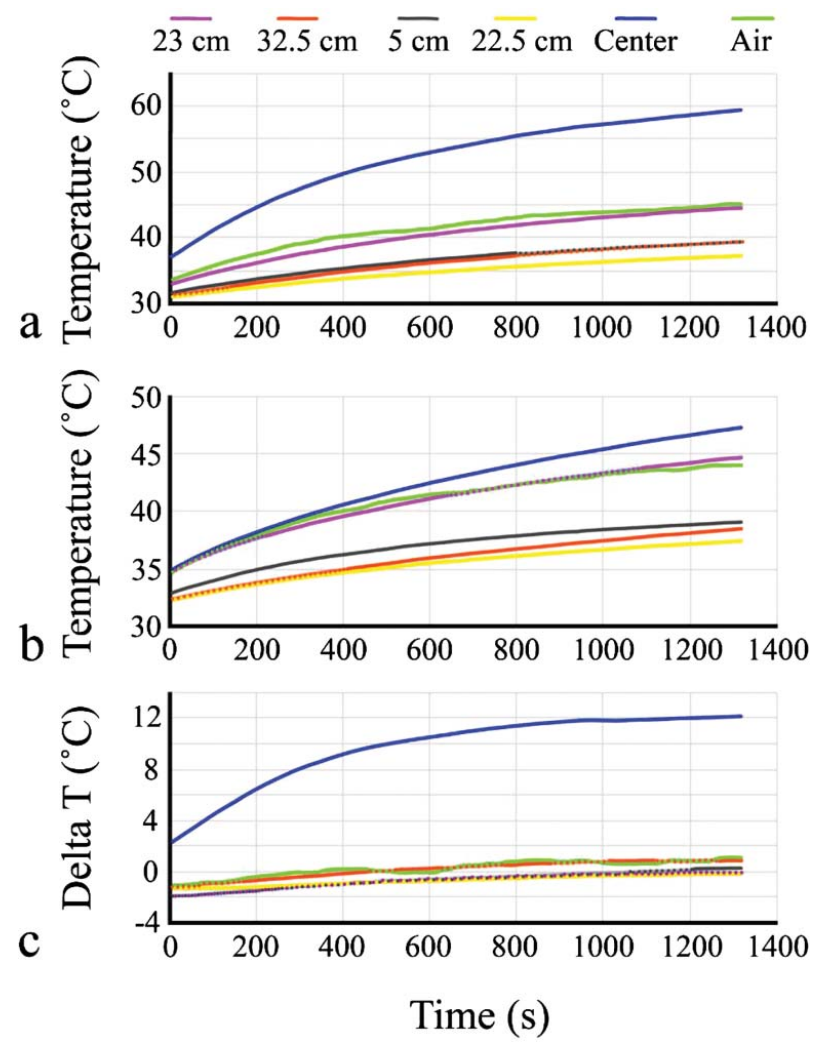

Figure 3. Average heating profiles $(n=3)$ recorded at six locations across the bottom of an empty refuge under conditions (a) without a water bag, (b) with a water bag, and (c) the temperature differences between these two treatments. The difference values were calculated as $T$ (no water) $-T$ (water) for each position at the same time. Locations given are the distance of bottom thermocouple probes from the exit: $23 \mathrm{~cm}$ was in the corner directly across the refuge from the exit, $32.5 \mathrm{~cm}$ was in the corner diagonally across the refuge from the exit, $22.5 \mathrm{~cm}$ was at the corner on the same side as the exit, $5 \mathrm{~cm}$ was immediately in front of the exit, and center was directly below the heat source. Where lines overlap, one line is dotted to improve legibility.

calculate the time needed to warm a pallet or container of size $x$ and contents $y$ to temperature $z$. We give some examples of required heating times for pallets of different masses and contents in Table 9. Times needed

Table 8. Average black-body equivalent temperature $\left(T_{e}\right)$ and corresponding radiation environment $(R)$ for snakes at the time of first observed movement and at time of exit from the refuge. Ranges are shown in parentheses.

\begin{tabular}{lllll}
\hline Treatment & \multicolumn{1}{c}{ Behavior } & $N$ & $T_{e}\left({ }^{\circ} \mathrm{C}\right)$ & $R\left(\mathrm{~W} / \mathrm{m}^{2}\right)$ \\
\hline No water & First movement & 31 & $44.4 \pm 3.0(38.2-48.9)$ & $577.1 \pm 21.1(534.2-609.1)$ \\
& Refuge exit & 35 & $47.4 \pm 2.2(41.5-50.3)$ & $598.8 \pm 15.3(557.2-619.5)$ \\
Water & First movement & 27 & $46.8 \pm 1.8(43.2-49.5)$ & $594.6 \pm 12.4(569.3-613.3)$ \\
& Refuge exit & 30 & $47.9 \pm 1.5(44.7-49.9)$ & $602.5 \pm 11.0(579.7-616.5)$ \\
\hline
\end{tabular}


Table 9. Estimated times to achieve internal temperatures of 41 or $47.7^{\circ} \mathrm{C}$ in model pallets having cargo contents spanning a representative range of specific heats. Initial temperature for each pallet was assigned to be $30{ }^{\circ} \mathrm{C} ; 47.7{ }^{\circ} \mathrm{C}$ is the average $T_{e}$ values at time of refuge exit calculated from our trials. For a $T_{e}$ of $47.7^{\circ} \mathrm{C}$, the radiation environment is $598 \mathrm{~W} / \mathrm{m}^{2}$; for a $T_{e}$ of $41^{\circ} \mathrm{C}$, it is $546.7 \mathrm{~W} / \mathrm{m}^{2}$.

\begin{tabular}{|c|c|c|c|c|}
\hline \multirow[b]{2}{*}{ Parameter } & \multicolumn{4}{|c|}{ Cargo contents } \\
\hline & $\begin{array}{c}\text { Paper towels } \\
\text { (packages of } 6, \\
6 \text { packages/tier, } 4 \text { tiers) }\end{array}$ & $\begin{array}{c}\text { Bottled water } \\
\text { (24500 mL bottles/ } \\
\text { pack, } 84 \text { packs/pallet) }\end{array}$ & $\begin{array}{l}\text { Electrical junction boxes } \\
(25.4 \mathrm{~cm} \times 30.5 \mathrm{~cm} \times \\
15.2 \mathrm{~cm}, 96 / \text { pallet })\end{array}$ & $\begin{array}{c}\text { Tool boxes }(86 \mathrm{~cm} \times 48 \mathrm{~cm} \\
\times 96.5 \mathrm{~cm}, 4 / \text { pallet, each } \\
\text { crated in } 1.3 \mathrm{~cm} \text { pine })\end{array}$ \\
\hline Pallet volume $\left(\mathrm{m}^{3}\right)$ & 0.85 & 1.02 & 1.13 & 1.98 \\
\hline Pallet surface area $\left(\mathrm{m}^{2}\right)$ & 5.4 & 6.1 & 6.6 & 10.3 \\
\hline Pallet mass (kg) & 442.9 & 967.7 & 441.4 & 698.2 \\
\hline Density of material $\left(\mathrm{kg} / \mathrm{m}^{3}\right)$ & 750 & 1000 & 7820 & 7820 \\
\hline Specific heat $(\mathrm{kJ} / \mathrm{kg} / \mathrm{K})$ & 1.336 & 4.186 & 0.49 & 0.49 \\
\hline Time to equilibrate (min) @ $47.7^{\circ} \mathrm{C}$ & 54.1 & 325.5 & 16.1 & 17.5 \\
\hline Energy requirement @ $47.7^{\circ} \mathrm{C}(\mathrm{kJ})$ & 10,472 & 71,698 & 3829 & 6504 \\
\hline Time to equilibrate (min) @ $41^{\circ} \mathrm{C}$ & 36.8 & 221.5 & 10.9 & 12.4 \\
\hline Energy requirement @ $41^{\circ} \mathrm{C}(\mathrm{kJ})$ & 6508 & 44,558 & 2379 & 4207 \\
\hline
\end{tabular}

to thoroughly heat the contents to lethal temperatures are not large, ranging from 11-326 $\mathrm{min}$ in the examples given (Table 9).

\section{Discussion}

Previously, we demonstrated that brown tree snakes will exit experimental refuges in under 5 min when air heated to $48-52{ }^{\circ} \mathrm{C}$ is blown past them (Kraus et al. 2015a). For that convective heat transfer, time required to induce exit was determined by rate of heat transfer to the snake, which was negatively related to air speed and positively related to refuge size. However, use of convective heating as a snake fumigant is limited to those circumstances allowing free passage of the heated airstream. In circumstances such as packed cargo, in which air flow is liable to be blocked in one or more directions, convective heating is ineffective, leading us to assess whether radiative heat transfer could be used in its stead. Our results make clear that it can be highly effective but only under controlled situations.

Radiative treatment of cargo containers and pallets would be easiest if these items could simply be left to warm sufficiently in the tropical sunlight. Packed pallets and containers are routinely stored on the tarmacs at AAFB for periods ranging from hours to days, so if passive solar heating introduced sufficient thermal energy, this would be an easy means of thermally treating cargo for brown tree snakes. However, our results make clear that this alone is not a viable treatment strategy. Cargo and containers rarely and unreliably reached temperatures sufficient to kill brown tree snakes (Tables 2-4). Even when lethal temperatures $\left(\geq 41{ }^{\circ} \mathrm{C}\right)$ were attained, these typically were achieved only at particular regions of the item most directly exposed to the sun (often the top or outer side surfaces) but were not uniformly met throughout the item. Hence, snakes would rarely be denied a thermally acceptable refuge throughout an entire pallet/container; in consequence, they would have no reason to leave its shelter for the nocuous bright, hot conditions of an open tarmac.
Ineffectiveness of passive solar heating was because variable cloud cover and cooling winds and rain showers did not allow the required temperatures to be reached in most pallets/containers. Even on days when solar irradiance was more evenly high, internal shading provided by the pallet or container itself - coupled with cooling winds across the cargo units' surfaces precluded reaching uniformly lethal temperatures throughout virtually every pallet/container examined (Table 4). The few exceptions observed were merely emply LD-3 containers, which are not typically stored on outside tarmacs anyway. Our data were taken during the months of May, June, November, and December, months having average cloud covers of 30\%-40\% and an average of $7-11$ days with rain (Table 5). These were middling values for Guam, and the months of our studies have the fewest numbers of overcast days, on average (Table 5), so there is no reason to expect other times of year to have weather conditions consistently more conducive to successful use of solar irradiation for thermal sterilization. Hence, passive solar irradiation of cargo is infeasible for use as a snake treatment to prevent their spread to other islands.

Data obtained from our bench-top experiments with long-wave radiative heating were more promising for developing management options. Times for snakes to exit the refuge were longer for these radiative-heat trials than seen in our convection work, taking 180-1451 s (Table 6) vs. 14-251 s for the latter (Kraus et al. 2015a), but all snakes were induced to exit. Snakes responded to somewhat lower temperatures in the present trials than they did in the convective trials (see below), but the slower pace of heat transfer to the snakes is what accounted for the longer response times. The details of these responses are illuminating.

In trials without the thermally buffering water bag below the test refuge, snake exit was determined by air temperature, whereas in the trials with the water bag, snake exit was determined by a combination of air temperature, bottom temperature, and the interaction between the two (Table 7). This accords with 
our expectations. In trials without the water bag, the bottom of the refuge directly below the heat source became hotter than it did during the trials with the water bag (Figure 3). However, snakes merely responded to that central hotspot by remaining in or retreating to one of the corners of the refuge, all of which were cooler (Figure 3). Thus, that central surface hotspot remained irrelevant to snake behavior: snakes exited the refuge when the air temperature became uncomfortable, leaving them no more thermal refuges in the test chamber's corners. In contrast, adding the water bag to absorb the incoming thermal energy directly below the heat source and disperse it across the bottom of the refuge served both to reduce temperature variation across the bottom and to more tightly couple the air and bottom temperatures during those trials, making for a more complicated but uniform thermal mass in the refuge. As a result, the best predictive models for snake response in those trials included all temperature data, indicating the snakes were responding to the total thermal environment of the refuge instead of just air temperature (Table 7).

Overall, the requirements for snake exit of a refuge - under either convective or radiative heating may best be compared by looking at the total thermal environment that the snake is responding to. In our earlier convection experiments (Kraus et al. 2015a) snakes responded to air streams heated to $48-52{ }^{\circ} \mathrm{C}$, corresponding to $T_{e}$ 's at the time of refuge exit that varied from 35.5 to $54.5{ }^{\circ} \mathrm{C}$ and averaged $49-52{ }^{\circ} \mathrm{C}$, depending on the experimental conditions. In contrast, snakes exited the refuge during our radiativeheating trials at $T_{e}$ 's varying from 41.5 to $50.3{ }^{\circ} \mathrm{C}$ and averaging $47.4-47.9^{\circ} \mathrm{C}$ (Table 8). The radiative trials provided a tighter range of $T_{e}$ 's and lower averages because less of the thermal energy introduced to the system is lost, as it unavoidably is in the application of streams of heated air. Furthermore, snakes clearly began looking for an exit to their increasingly warm refuges at temperatures varying from 38.9 to $53.9^{\circ} \mathrm{C}$ and averaging $47.8-49.0^{\circ} \mathrm{C}$ for convective heating and varying from 38.2 to $49.5^{\circ} \mathrm{C}$ and averaging $44.4-$ $46.8{ }^{\circ} \mathrm{C}$ for radiative heating (Table 8). Again, the radiative trials provided a tighter range of $T_{e}$ 's and lower averages than did the convective trials. Results for both the convective and radiative heating studies make clear that snakes respond relatively quickly to temperatures approaching or exceeding by a few degrees their upper lethal limit of $41{ }^{\circ} \mathrm{C}$. None of these temperatures is problematic for the vast majority of packed goods on Guam.

Snakes responded to radiation environments of about $530-620 \mathrm{~W} / \mathrm{m}^{2}$ (Table 8 ), which correspond to solar irradiance values under light cloud conditions. Despite this, as we saw earlier, variable weather conditions and exposure to cooling winds precluded consistent attainment of lethal temperatures via passive solar radiation even under such solar irradiance regimes on Guam. Theoretically, this energy deficit could potentially be overcome by adding a thermal boost to exposed pallets or containers, perhaps with a portable heating unit. However, any such heating unit would likely require introducing forced warm air and would run into the problem already discussed in use of convective heating systems: the requirement for free air flow. That will not be met for most closely packed cargo pallets or containers. Furthermore, if left exposed on the tarmac, pallets/containers would still be exposed to wind flow that would reduce the efficiency of thermal boosting.

An alternative system immediately suggests itself as operationally easier and more reliable. Placement of packed pallets and containers in an enclosure maintained at a temperature slightly above the lethal temperature for brown tree snakes could quickly produce uniformly lethal temperatures throughout the contents via radiative heating. The enclosure would need to be insulated to minimize heat loss to the environment. Placement of the enclosure on an open tarmac would ensure the minimal temperature gradient between the enclosure's environment and its heated internal space, thereby reducing heating costs, as would enclosure construction using heat-absorbent materials. Required heating times would vary depending on cargo mass and composition. For illustrative purposes, simple estimates for mock-up pallets comprising contents of widely varying densities and specific heats show that pallets can be uniformly heated to temperatures lethal for snakes in times ranging from a few minutes to a few hours (Table 9). We provide two temperature endpoints for our illustration: $41^{\circ} \mathrm{C}$ because it is the upper lethal temperature for brown tree snakes, and $47.7^{\circ} \mathrm{C}$ because it was the overall average temperature at which snakes exited the refuge in our experiments. Other values could be used, but these bracket a reasonable range of target temperatures that could be chosen for cargo treatment. Heating to $41{ }^{\circ} \mathrm{C}$ would require that end temperature be held for at least $1 \mathrm{~h}$, as that is the time needed for that temperature to prove reliably lethal to brown tree snakes (Christy et al. 2007). Slightly higher target temperatures would no doubt need to be maintained for shorter durations.

Differences in times observed to achieve sufficient warming in our experimental apparatus to elicit snake exit vs. those estimated to heat entire pallets in the scenarios explored in Table 9 reflect the differing properties between our experimental system and that evaluated in the models. The test apparatus used by us was heated non-uniformly on a single side, whereas the modeled cargo scenarios assume all chamber surfaces are heated uniformly at 41 or $47.7^{\circ} \mathrm{C}$. The heat source in our test apparatus was an IR lamp with a surface diameter of $6.4 \mathrm{~cm}$, which is a considerably 
different thermal environment than that provided by having the entire surface area of a cargo container heated uniformly at a specified temperature. Consequently, the relatively slow response times observed for snakes in our study should not be mistakently extrapolated to heating behavior for cargo held within a warmed enclosure.

Several advantages would accrue to using radiative heating of cargo in an enclosure to treat for snakes. First, times required for treatment are short enough to be feasible within the operational parameters of ordinary cargo handling, which normally has packed cargo staged in waiting areas for hours or days. Second, the method is relatively cheap, safe, and easy to apply. Required temperatures are not extreme to humans or the vast majority of cargo items; enclosures/small buildings are relatively easy to heat and, if the enclosure were properly insulated, internal temperatures could be maintained at low cost; and the only treatment method required would be to run pallets/containers into and out of the enclosure on a forklift, which is standard cargo-handling procedure anyway. Third, such a treatment enclosure need not be large, so its areal footprint need not conflict with existing facilities. Fourth, this method need not be concerned with inducing snakes to exit cargo in order to be successful as would, say, the use of chemical irritants or convective heating. The limitation of those methods is that when the irritating stimulus is removed, the snake may still remain in the cargo container if it was unable to find a means of exit. For radiative heating, whether a snake exits the cargo or dies in situ is immaterial to success, provided the end temperature is maintained for a sufficient duration to ensure snake death. Currently, we know that an end temperature of $41{ }^{\circ} \mathrm{C}$ maintained for $1 \mathrm{~h}$ will prove invariably lethal to brown tree snakes. Slightly higher temperatures would undoubtedly require shorter durations, and it is a matter of simple experiment to determine what those durations would be. There seems little reason to expect radiative heating to higher than $43-44{ }^{\circ} \mathrm{C}$ to be required for successfully sterilizing cargo outbound from Guam.

One final consideration is that such a simple treatment method could potentially be applied to protect against a diversity of invasive ectotherms beyond just snakes. Many damaging animals continue to be introduced outside their native ranges through cargo shipments (e.g. Cowie \& Robinson 2003; Work et al. 2005; Kraus 2009). Creating standard procedures to radiatively heat cargo items that are not liable to damage from heating to $45-50{ }^{\circ} \mathrm{C}$ may serve as a reliable means of protecting importing localities from a host of potentially damaging new invasions. It is likely that few invasive ectotherms can withstand those temperatures for long, and the costs saved in avoiding further invasions would seem likely to merit the costs of such protective sterilization.

\section{Acknowledgments}

This study was approved as NWRC Protocol QA-2312 and Protocol QA-2528 and funded by the Department of Interior's Office for Insular Affairs (Cooperative Agreement Number 14-7415-1100). We thank C. Clark, J. Guerrero, M. Hall, T. Salas, and D. Vice for logistical assistance on Guam; Msgt. Y. Espina, Sgt. C. Ginbey, Msgt. F. Halili, Msgt. R. Upton, and Mr. M. Weathers for kindly providing access to their cargo facilities for placing our temperature probes; M. Hall for providing the photo of an ISU-90; and the AAFB snake crew for providing us with test animals and generously allowing us work room in their facilities.

\section{Disclosure statement}

No potential conflict of interest was reported by the authors.

\section{Funding}

This work was supported by Department of Interior's Office for Insular Affairs (Cooperative Agreement Number 14-7415-1100).

\section{References}

Anderson DR. 2007. Model based inference in the life sciences: a primer on evidence. New York: Springer Science \& Business Media.

Burnett K, Kaiser B, Pitafi BA, Roumasset R. 2006. Prevention, eradication, and containment of invasive species: illustrations from Hawaii. Agr Res Econ Rev. 35:63-77.

Campbell GS. 1977. An introduction to environmental biophysics. New York (NY): Springer-Verlag.

Christy MT, Savidge JA, Bischof R, Rodda GH. 2007. Can temperature be used as a tool for limiting brown tree snake invasion via transportation pathways? In: Witmer GW, Pitt WC, Fagerstone KA, editors. Managing vertebrate invasive species: proceedings of an international symposium. Fort Collins (CO): USDA/APHIS/Wildlife Services, National Wildlife Research Center; p. 246-256.

Cowie RH, Robinson DG. 2003. Pathways of introduction of nonindigenous land and freshwater snails and slugs. In: Ruiz GM, Carlton JT, editors. Invasive species: vectors and management strategies. Washington (DC): Island Press; p. 93-122.

Engeman RM, Vice DS, Rodriguez DV, Gruver KS, Santos WS, Pitzler ME. 1998. Effectiveness of detector dogs for locating brown tree snakes in cargo. Pac Conserv Biol. 4:256-260.

Engeman RM, Vice DS, York D, Gruver KS. 2002. Sustained evaluation of the effectiveness of detector dogs for locating brown tree snakes in cargo outbound from Guam. Int Biodeterior Biodegr. 49:101-106.

Fritts TH, Chiszar D. 1999. Snakes on electrical transmission lines: patterns, causes, and strategies for reducing electrical outages due to snakes. In: Rodda GH, Sawai Y, Chiszar D, Tanaka H, editors. Problem snake management: the habu and brown tree snake. Ithaca (NY): Comstock Publication; p. 89-103.

Fritts TH, McCoid MJ. 1991. Predation by the brown tree snake Boiga irregularis on poultry and other domesticated animals in Guam. Snake. 23:75-80.

Fritts TH, McCoid MJ. 1999. The threat to humans from snakebite by snakes of the genus Boiga based on data 
from Guam and other areas. In: Rodda GH, Sawai Y, Chiszar D, Tanaka H, editors. Problem snake management: the habu and brown tree snake. Ithaca (NY): Comstock Publication; p. 116-127.

Fritts TH, Rodda GH. 1998. The role of introduced species in the degradation of island ecosystems: a case history of Guam. Ann Rev Ecol Syst. 29:113-140.

Fritts TH, Scott NJ Jr, Savidge JA. 1987. Activity of the arboreal brown tree snake (Boiga irregularis) on Guam as determined by electrical outages. Snake. 19:51-58.

Fritts TH, McCoid MJ, Haddock RL. 1990. Risks to infants on Guam from bites of the brown tree snake (Boiga irregularis). Amer J Trop Med Hyg. 42:607-611.

Fritts TH, McCoid MJ, Haddock RL. 1994. Symptoms and circumstances associated with bites by the brown tree snake (Colubridae: Boiga irregularis) on Guam. J Herpet. 28:27-33.

Kraus F. 2009. Alien reptiles and amphibians: a scientific compendium and analysis. Dordrecht: Springer Science and Business Media B.V.

Kraus F, Stahl R, Pitt W. 2015a. Thermal fumigation provides a simple and effective solution for sanitizing cargo from invasive snakes. J Pest Sci. 88:331-341.

Kraus F, Stahl R, Pitt W. 2015b. Chemical repellents appear non-useful for eliciting exit of brown tree snakes from cargo. Int J Pest Manag. 61:144-152.

Olmsted J III, Williams GM. 1997. Chemistry: the molecular science. Dubuque (IA): William C. Brown Publishers.
Perry G, Vice DS. 2007. An evaluation of passive thermal fumigation from brown tree snake control in surface transportation from Guam. In: Witmer GW, Pitt WC, Fagerstone KA, editors. Managing vertebrate invasive species: proceedings of an international symposium. Fort Collins (CO): USDA/APHIS/Wildlife Services, National Wildlife Research Center; p. 224-233.

Rodda GH, Savidge JA. 2007. Biology and impacts of Pacific Island invasive species. 2. Boiga irregularis, the brown tree snake (Reptilia: Colubridae). Pac Sci. 61:307-324.

Rodda GH, Fritts TH, Chiszar D. 1997. The disappearance of Guam's wildlife: new insights for herpetology, evolutionary ecology, and conservation. BioScience. 47:565-574.

Savidge JA. 1987. Extinction of an island forest avifauna by an introduced snake. Ecology 68:660-668.

Shwiff SA, Gebhardt K, Kirkpatrick KN, Shwiff SS. 2010. Potential economic damage from introduction of brown tree snakes, Boiga irregularis (Reptilia: Colubridae), to the islands of Hawai'i. Pac Sci. 64:1-10.

Vice DS, Engeman RM, Hall MA, Clark CS. 2009. Working dogs: the last line of defense for preventing dispersal of brown tree snakes from Guam. In: Helton WS, editor. Canine ergonomics: the science of working dogs. Boca Raton (FL): CRC Press; p. 195-204.

Work TT, McCullough DG, Cavey JF, Komsa R. 2005. Arrival rate of nonindigenous insect species into the United States through foreign trade. Biol Inv. 7:323-332. 